\title{
MicroRNAs: an emerging science in cancer epigenetics
}

\author{
Rishabh Kala', Gregory W Peek', Tabitha M Hardy ${ }^{1}$ and Trygve O Tollefsbol ${ }^{1,2,3,4,5^{*}}$
}

\begin{abstract}
MicroRNAs (miRNAs) are remarkable molecules that appear to have a fundamental role in the biology of the cell. They constitute a class of non-protein encoding RNA molecules which have now emerged as key players in regulating the activity of mRNA. miRNAs are small RNAmolecules around 22 nucleotides in length, which affect the activity of specific mRNA, directly degrading it and/or preventing its translation into protein. The science of miRNAs holds them as candidate biomarkers for the early detection and management of cancer. There is also considerable excitement for the use of miRNAs as a novel class of therapeutic targets and as a new class of therapeutic agents for the treatment of cancers. From a clinical perspective, miRNAs can induce a number of effects and may have a diverse application in biomedical research. This review highlights the general mode of action of miRNAs, their biogenesis, the effect of diet on miRNA expression and the impact of miRNAs on cancer epigenetics and drug resistance in various cancers. Further we also provide emphasis on bioinformatics software which can be used to determine potential targets of miRNAs.
\end{abstract}

Keywords: miRNA, Biogenesis, Diet, Cancer epigenetics, Bioinformatics software

\section{Introduction}

MicroRNAs (miRNAs) are a group of endogenous small and noncoding RNAs that are approximately 18-25 nucleotides in length that play a critical role in the regulation of gene expression. In the past decade, the biological functions and biogenesis of miRNAs have become popular topics for biomedical research. As expected, miRNA expression is highly correlated with human diseases, such as cancer and other aging associated diseases. miRNAs may function not only as oncogenes but also as tumor suppressors, further implicating their roles as therapeutic targets. Moreover, miRNAs can be used as biomarker or prognostic signature molecules for determining the likely outcome of certain diseases such as cancer. The importance of these small noncoding RNA molecules in predicting the outcome of various cancers has been highlighted. Previous study on human patients emphasizes the substantial role of this

\footnotetext{
* Correspondence: trygve@uab.edu

'Department of Biology, University of Alabama Birmingham, 1300 University Boulevard, Birmingham, AL 35294, USA

${ }^{2}$ Center for Aging, University of Alabama Birmingham, 1530 3rd Avenue South, Birmingham, AL 35294, USA

Full list of author information is available at the end of the article
}

relatively newly identified class of RNA molecules as diagnostic and prognostic biomarkers in cancers [1].

\section{miRNA biogenesis and its mode of action}

The miRNAs undergo a relatively complicated biogenesis (Figure 1) that starts with their synthesis as long primary transcripts (pri-miRNA) by RNA polymerase II [2]. This long primary transcript is then further cleaved by Drosha, an RNase III nuclear enzyme which liberates a 60-to 70-nucleotide stem loop intermediate known as the miRNA precursor (pre-miRNAs) [3,4]. Because of the self-complementarity within the RNA molecule, this precursor molecule forms a characteristic hairpin double-strand. The pre-miRNAs are transported from the nucleus to the cytoplasm by Exportin-5, and are further processed by Dicer, a second RNase III enzyme [5]. The role of Dicer is to cleave pre-miRNA molecules to produce 22 basepair dsRNA molecules. One strand (the active, or "guide" strand) is then loaded into the RNA-induced silencing complex (RISC), while the inactive strand, also called a "passenger" strand, is removed and degraded. Through sequence-specific interactions between the mature miRNAs and mRNA, the 


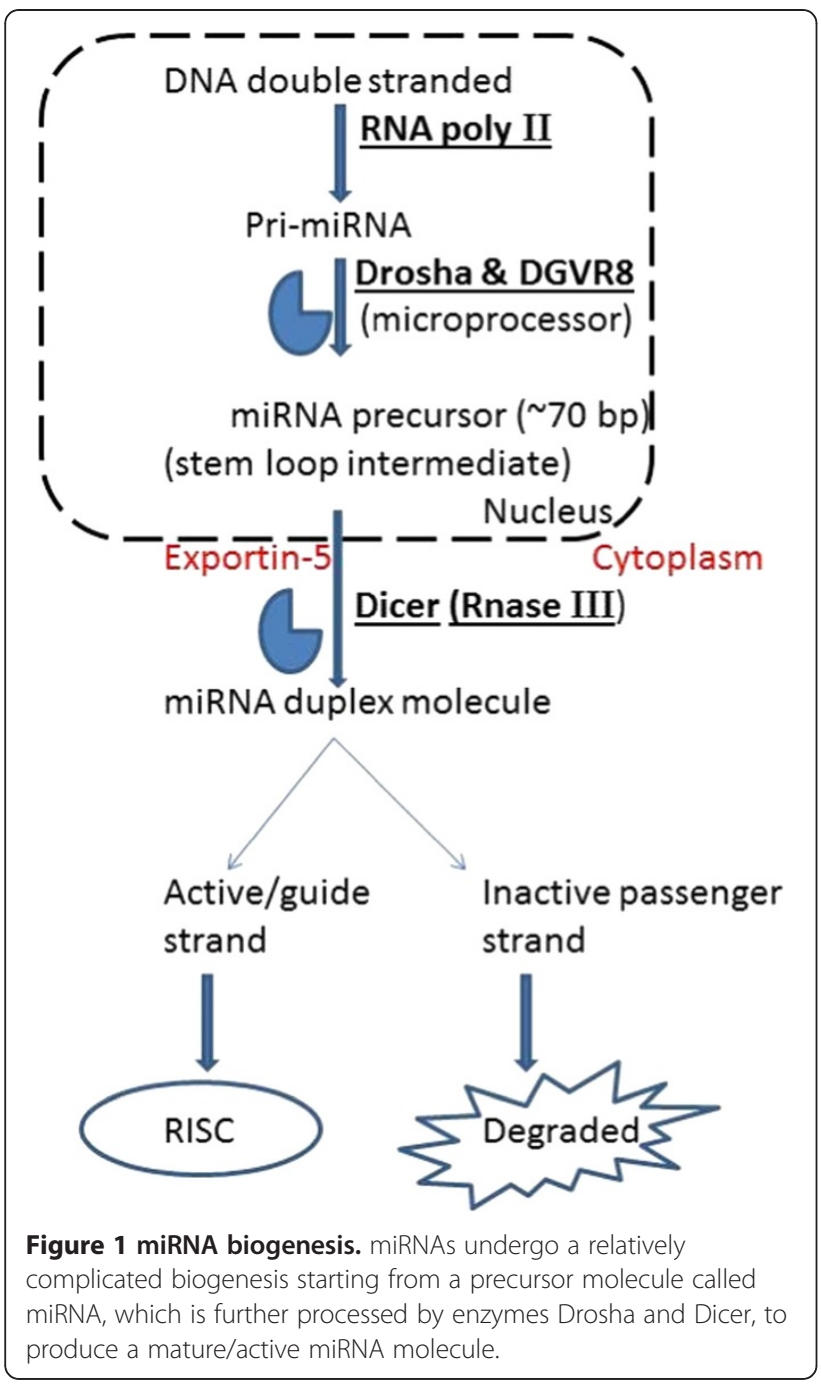

ribonucleoprotein complex is positioned on either of the two untranslated regions (UTR) of their targets [5-8].

RISC is composed of the transactivation-responsive RNA binding protein (TRBP) and Argonaute (Argo), the catalytic component of RISC complex. The guide strand can then recognize the complementary sequence of mRNA via its association with RISC. miRNA target recognition involves base-pairing between nucleotides 2-7 (the seed) of the $5^{\prime}$ end of the miRNAs and a 6,7 or 8 nucleotide sequence of the mRNA $3^{\prime}$ UTR, with additional less absolute requirements $[9,10]$. These include (1) the fidelity of seed base-pairing to short $3^{\prime}$ UTR motifs, (2) high A and U content in the nucleotides surrounding the seed-binding motif, (3) location of the $3^{\prime}$ UTR binding site at least 15 nucleotides past the stop codon, (4) seed-binding motif avoidance of any location near the center of a long $3^{\prime}$ UTR, and (5) seed-binding motif location close to supplemental UTR pairing with miRNA nucleotides 13-16 [9]. Although it is known that a single species of miRNA can affect the expression levels of many genes, it is not yet clear how the specificity of this function of miRNAs is regulated. These noncoding RNA molecules are evolutionarily conserved and can be located in the introns or exons of genes, or in the sequence between genes (intergenic sequence) and are assumed to be involved in development, cell differentiation, metabolic pathways, signal transduction, proliferation, and apoptosis [6].

During the process of biogenesis there are a host of mechanisms that govern the transcription and posttranscriptional regulation of the miRNAs. The discovery of these mechanisms has enhanced our understanding of miRNA deregulation in a variety of disease states, including cancer, although much work remains for a more complete understanding of miRNA-mediated regulation of gene expression and downstream effects. Examples involve regulatory proteins Dicer and Drosha, with downregulation of Dicer and Drosha believed to affect miRNA expression level and increase risk in neuroblastoma tumors. In fact, an important study has shown that in vitro knockdown of Dicer and Drosha promoted the growth of neuroblastoma cell lines [11].

miRNAs have emerged as new targets in biomedical studies because of their effects on a number of biological phenomena with reported impact on various diseases including ageassociated diseases such as cancer. In light of miRNA involvement in cancer-associated genomic alterations, high-throughput technologies for assessing miRNAs have been developed to study the global miRNA expression patterns in cancer called the miRNAome (Table 1). With the onset of next-generation sequencing, the repertoire of experimentally verified mature miRNA has rapidly expanded [12,13]. Current methodology, as well as an extensive miRNA database, is presented or identified by miRBase, available at http://microrna.sanger.ac. $\mathrm{uk} /$ or http://www.mirbase.org/. It is maintained by the University of Manchester and can be searched by accession number, name, keyword, chromosome location, tissue expression, sequence, homologous sequence or PubMed ID. miRBase is updated frequently with the recently described version miRBase 16 containing over 17,000 miRNA sequences from over 140 species updated in August 2012 (miRBase 19) to over 25,000 mature sequences [13].

Useful software for determining miRNA targets has now begun to proliferate [14-16]. Software of particular interest is miRanda, available at http://microrna.org or via miRBase (miRBase Targets) $[15,17,18]$. miRanda uses data from the genomic database Ensembl, available at http://www.ensembl.org/ [17,19], which allows a user to determine the target genes of a specific miRNA, the miRNAs for which a specific gene is a target and the expression profile of a specific miRNA [15]. miRanda accommodates the identification of both conserved and 
Table 1 Databases and software used in miRNA analysis

\begin{tabular}{|c|c|c|c|}
\hline Database or software & Principal applications & Additional features & Search by \\
\hline $\begin{array}{l}\text { miRBase } \\
\text { (http://microrna.sanger.ac.uk/ or } \\
\text { http://www.mirbase.org/) }\end{array}$ & $\begin{array}{l}\text { miRNA target } \\
\text { identification }\end{array}$ & $\begin{array}{l}\text { Links to databases and software, } \\
\text { such as miRanda }\end{array}$ & $\begin{array}{l}\text { Accession number, } \\
\text { name, keyword tissue, } \\
\text { sequence PubMed ID }\end{array}$ \\
\hline $\begin{array}{l}\text { miRanda } \\
\text { (http://microrna.org) }\end{array}$ & $\begin{array}{l}\text { Identification of target genes } \\
\text { or targeting miRNA. miRNA } \\
\text { expression profile and } \\
\text { distinguish conserved } \\
\text { and non-canonical sites }\end{array}$ & $\begin{array}{l}\text { Support vector regression } \\
\text { (SVR) algorithm to determine } \\
\text { level of gene down-regulation. }\end{array}$ & miRNA, target gene \\
\hline $\begin{array}{l}\text { TarBase } \\
\text { (http://microrna.gr/) }\end{array}$ & miRNA target identification & & miRNA \\
\hline $\begin{array}{l}\text { miR2Disease } \\
\text { (http://www.miR2Disease.org) }\end{array}$ & $\begin{array}{l}\text { Associate human } \\
\text { diseases with specific } \\
\text { miRNA dysregulation }\end{array}$ & Uses TarBase & $\begin{array}{l}\text { Specific miRNA, } \\
\text { disease name, tissue } \\
\text { or target gene }\end{array}$ \\
\hline $\begin{array}{l}\text { TransmiR } \\
\text { (http://cmbi.bjmu.edu.cn/transmir) }\end{array}$ & $\begin{array}{l}\text { Identify transcription } \\
\text { factors that regulate } \\
\text { specific miRNA }\end{array}$ & $\begin{array}{l}\text { Links to } \mathrm{NCBI} \text { gene and } \\
\text { protein data and literature }\end{array}$ & $\begin{array}{l}\text { Transcription factor names, } \\
\text { miRNA name, species, } \\
\text { regulation type, literature }\end{array}$ \\
\hline $\begin{array}{l}\text { miRTarBase } \\
\text { (http://miRTarBase.mbc.nctu.edu.tw/) }\end{array}$ & $\begin{array}{l}\text { Document experimentally confirmed miRNA- } \\
\text { target interactions }\end{array}$ & $\begin{array}{l}\text { Provides method of } \\
\text { interaction confirmation, } \\
\text { information on mature } \\
\text { miRNA and precursor, } \\
\text { expression profile, gene } \\
\text { target network }\end{array}$ & $\begin{array}{l}\text { Species, miRNA, } \\
\text { target gene combination }\end{array}$ \\
\hline
\end{tabular}

nonconserved target sites which can be individually evaluated by the support vector regression (SVR) algorithm for degree and rank of capacity for gene downregulation [20]. The mirSVR algorithm was designed for ranking the level of down-regulation associated with miRandadesignated target sites according to miRNA transfection and inhibition experiments [9,20]. The mirSVR scores, which simulate down-regulation predictions, were found to be especially valuable for recognizing gene down-regulation by multiple miRNAs, and they are provided on the miRanda website [20].

The database miR2Disease provides extensive inventory and documentation of involvement of miRNA dysregulation in human disease and is available at http:// www.miR2Disease.org [21]. As of the March 2011 update, miR2Disease provided comprehensive documentation of miRNA dysregulation of 349 miRNAs associated with 163 diseases including age-associated disease like cancer [21]. Access is provided by search via specific miRNA, disease name (and associated tissue) or experimentally validated target gene (from TarBase). Detailed analysis is provided by links to referenced literature.

The database TransmiR, available at http://cmbi.bjmu. edu.cn/transmir, documents miRNA regulation by transcription factors and thus provides a critical link to origins of gene dysregulation by miRNA and any consequent disease etiology [22]. As of the March 2012 update, TransmiR documents 201 transcription factors and 209 miRNAs from 16 organisms [22]. It can be assessed by combinations of transcription factor name, miRNA name, species, regulation type (activate or repress) and/ or PubMedID. Links are provided to NCBI gene and protein data along with associated literature and networks of transcription factors and their target miRNA genes are included [22].

miRTarBase at http://miRTarBase.mbc.nctu.edu.tw/ is an extensive database of experimentally confirmed miRNA-target interactions. These interactions are experimentally validated using Western blot, knockdown or reporter gene analysis [23]. The miRTarBase database released in October 2011 included 669 miRNAs and 2553 target genes of 14 species [23]. The networks of mature miRNA and gene targets appear to be suitable for potential integration with protein-protein interaction networks as well as network data derived from TransmiR [22,23].

\section{miRNAs and cancer epigenetics}

miRNAs are emerging as a new class of molecules whose deregulation may ultimately contribute to cancer formation. They also likely cooperate with the other classic oncogenes and/or down-regulate tumor suppressor genes in cancer cells to drive the behavior of the tumors. Although many miRNAs have been shown to be deregulated in cancers, the set of miRNAs that actually play a pathogenic role in cancer has not yet been clearly determined. Additional changes in the expression level of miRNAs in cancer cell lines can directly regulate certain fundamental behaviors of cancer cells, such as proliferation and apoptosis [24]. Many of the miRNAs deregulated in cancers have been shown to have a direct impact on tumor suppression and their metastasis. 
These non-coding classes of RNA can serve as useful biomarkers and may greatly improve clinical management by better defining appropriate treatment options for patients [5].

In addition to their role in tumor suppression or tumor promotion, miRNAs have also been identified as master regulators of key genes implicated in mechanisms of chemoresistance. There are two main mechanisms which are thought to be the key players in chemoresistance: one is genetic and the other is epigenetic. Although evidence regarding genetic changes following chemotherapeutic treatment is limited, numerous studies have demonstrated significant epigenetic alterations in drug-resistant cancer cells $[25,26]$. In addition to these well-studied mechanisms of cancer drug resistance, there have been recent studies that link cancer drug resistance with the alteration of miRNAs expression [27].

Epigenetics is the study of heritable changes in gene expression caused by mechanisms other than changes in the underlying DNA sequences, which might affect various cellular phenomena like cell signaling, proliferation, apoptosis. Epigenetic processes are commonly thought to favor cell survival and tumor progression. Examples of epigenetic changes are DNA methylation and histone modifications, both of which serve to regulate gene expression without altering the underlying DNA sequence $[28,29]$. In order for DNA to undergo methylation and histone modifications, epigenetic modifying enzymes such as DNA methyltransferases (DNMTs), histone deacetylases (HDACs), histone acetylases (HAT) and histone demethylases (HDMs) are required. Interestingly, these miRNAs can control the expression of various epigenetic-modifying enzymes which are involved in carcinogenic processes [30,31]. There are a number of studies highlighting this connection. One such study was performed by Lujambio et al. in 2008 which showed that hypermethylation of miR-148 resulted in its downregulation because of positive feedback that exists to reinforce the overexpression of DNMTs in breast cancer cells which resulted in breast tumor growth and metastasis. Furthermore, the reactivation of miR-148 upon treatment with a DNA demethylating agent was associated with reduced tumor growth and inhibition of metastasis [32]. Another study involved comparison between normal lung cell and cancerous cells and reported an expressional difference of miRNA in both the cell types [33]. The miRNA-29 family (miRNA-29a,-29b,$29 c$ ), which is down-regulated in cancers, was shown to have some interesting complementarity with the 3/UTR of DNA methyltransferase (DNMT)3A and 3B both of which are known de novo methyltransferases. Further investigation determined whether $m i R-29 s$ could target DNMT3A and 3B expression by restoration of $m i R-29 s$. It was found that the enforced expression of $m i R-29 s$ in lung cancer cell lines restored normal patterns of DNA methylation and induced re-expression of methylationsilenced tumor suppressor genes, thus affecting cancer growth [33].

miRNAs are implicated in several cellular responses to drug exposure, including, but not limited to, drug influx/efflux, cell cycle arrest, DNA repair, and apoptosis, all of which mediate cancer cell survival and tumor progression. There have been a number of miRNAs which are reported to be involved in breast cancer drug resistance, one of which is $m i R-101$, which targets EZH2, the enzyme responsible for trimethylating histone $\mathrm{H} 3$ lysine 27 to establish a repressive chromatin state. miRNA upregulation has been linked to tamoxifen and fulvestrant resistance $[34,35]$. Crosstalk may occur between certain classes of miRNAs such as miR-101, miR206 , and $m i R-221 / 222$, which translationally repress the estrogen receptor alpha (ER $\alpha)$ and could also be responsible for the decreased sensitivity to anti-estrogen drugs $[27,34,35]$. Further, on comparing ER $\alpha$-negative breast cancer cells lines such as MDA-MB 468, HS578T and MDAMD-231 with ER $\alpha$-positive cell lines such as MCF7, T47D and MDA-MB 361, there was an expressional difference in $m i R-221$ and $m i R-222$. Further analysis revealed that knockdown of these two marker miRNAs partially restored ER $\alpha$ protein expression in ER $\alpha$ proteinnegative/ mRNA-positive cells, thus making them a potential biomarker for prognostic as well as therapeutic purposes [27]. These findings indicate a role for miRNAs in regulating estrogen receptor and drug resistance. Furthermore, since a number of miRNAs can target DNA and histone-modifying enzymes, they are likely to affect gene expression on a much broader scope.

The roles of miRNAs in cancers have been extensively investigated in the past few years. Recently, the connection of miRNA and tumor suppressor networks was elucidated. p53, a wellknown tumor suppressor, regulates diverse physical responses to many cancer-related stress signals, which may affect cell proliferation, cell death, DNA repair, and angiogenesis. Thus far results obtained are mixed. In some studies, p53 was found to affect miRNA expression and in other studies miRNAs were found to play a crucial role in p53-mediated tumor suppression [36]. A wide array of miRNAs were found to be affected by the expression level of this key tumor suppressor gene, including in colon cancer were p53 may have a direct role in miRNA expression [37]. In another study, 470 miRNAs were analyzed using microarray and 12 of these were found to be significantly affected by p53 [38]. Moreover, it has been found that miR-34a affects the pathway that mediates cellular aging and limits longevity, by mitigating SIRT1 expression and p53related apoptosis, stability and activity [39]. SIRT1, a mammalian homologue of yeast silent information 
regulatory Sir2, with an enzymatic activity of nicotinamide adenine dinucleotide (NAD+)-dependent histone deacetylases, is a class III histone deacetylase. $m i R-34 a$ is a tumor suppressor gene that is an evolutionarily conserved miRNA, with a single, recognizable orthologue in several invertebrate species [36]. $m i R-34 a$ functions as a tumor suppressor, in part, through a SIRT1-p53 pathway. This miRNA inhibits SIRT1 expression through a miR34a-binding site within the 3/ UTR of SIRT1. In support of this concept, it was discovered that miRNA did not affect the SIRT1 RNA transcription but it did affect the translation of SIRT1 RNA by acting on the 3/response element of SIRT-1 [39,40]. Xu et al. [40] reported an effort to use softwares such as miRnada, TargetScan, and Pic Tar, which could help in target prediction for miR-22 and miR-34a. Moreover, knockdown of miR-34a function by antisense oligonucleotides attenuates the acetylation of p53. miR-34a may have other targets besides SIRT1 that can regulate cell survival. Thus, SIRT1 may be one of several distinct targets of miR-34a that contribute to its ability to promote apoptosis.

Recently, a study was performed with 5-fluorouracil (5-FU)-resistant human colorectal cancer DLD-1 cells and with parental DLD-1 cells [41]. In that study the level of $m i R-34 a$ was observed to be low in the drug resistant cell line but it was found to be high in parental cells after treatment. Moreover with respect to SIRT-1 expression, $m i R-34 a$ was observed to be upregulated in resistant cells. Further activation of miR-34a resulted in inhibition of growth with a decrease in Sirt1 expression. These findings suggest that miR-34a targeting the Sirt1 genes could negatively regulate, at least in part, the resistance to 5-FU in human colorectal cancer DLD-1 cells [41].

The $m i R-200$ family is a crucial modulator of epithelial to mesenchymal transition (EMT), which is a normal embryological process involved in various adult pathologies including cancer metastasis and tumorigenicity. The miR-200 family is down-regulated and exhibits tumor suppressive properties in renal, prostate, breast, bladder, pancreatic, and gastric cancers. It is a key regulator of the epithelial phenotype and is involved in EMT processes in breast cancer. There have been a crosslinking reported between Class III histone deacetylase SIRT1, a proposed oncogene in breast cancer, and miR-200. With overexpressed SIRT1 an overexpression of EMT was observed due to a positive feedback loop between epigenetically silenced $m i R-200$ and SIRT1. Further restoration of $m i R-200$ or the knockdown of SIRT1 prevented transformation of normal mammary epithelial cells as evidenced by decreased breast cancer metastasis. Finally, it was observed that SIRT1 overexpression is associated with decreased miR-200a in breast cancer patient samples, indicating that $m i R-200 a$ may be a potential tumor suppression target in breast cancer metastasis [42]. Several other class of miRNAs have also been associated with 3/UTR of SIRT1, such as miR-34a, miR-132, and $m i R-199 a$ and this association is tissue specific and results in downregualtion of SIRT1 expression in colon, adipocyte, and cardiac tissues, respectively [39,43]. Another study using gastric cancer cell in a mouse model, showed overexpression of miR-499 resulted in decreased expression of SIRT1 which resulted in 60\% growth inhibition when compared with control. This was further shown using FACS analysis and $\beta$-Gal activity assays. Importantly, qPCR analysis also showed a loss of $m i R$ 499 expression in human clinical gastric tumor when compared with normal tissue [44]. Moreover, SIRT-1 protein level was found to be higher in mouse embryonic stem cells when compared with mouse differentiated tissues. Certain classes of miRNAs such as miR-9, miR-181a, miR-181b, miR-204, miR-199b, miR-135, post-transcriptionally downregulate SIRT1 levels in differentiated tissues [45]. Further, in support of a tumor suppressor role of miRNAs, a study was performed on T24 bladder cancer cells in which cells were treated with a DNA demethylating agent and HDAC inhibitors, which resulted in a decrease in DNA methylation and an increase in histone activation around the promoter region of the $m i R-127$ gene. This ultimately lead to increased expression of miR-127 and tumor inhibition [46].

Table 2 The effects of miRNA on target molecules

\begin{tabular}{lll}
\hline Target molecule in cancer & miRNA involved & Effects on target molecule \\
\hline SIRT1/HDAC III & $\begin{array}{l}\text { miR-34a, miR-22, miR-499, miR-200, } \\
\text { mi-9, miR-181a, miR-181b, miR-204, } \\
\text { miR-1996, miR-135 }\end{array}$ & Down-regulated \\
P53 & miR-34a & Upregulated \\
EMT & miR-200 & Down-regulated \\
DNMT & miR-148, miR-29a, miR-29b, miR-29C & Overexpression of DNMTs \\
EZH2 histone lysine methyltransferase & miR-101 & Upregulated and causes drug resistance in breast cancer \\
ER expression & miR-101, miR-206, miR-221/222 & Down-regulated \\
P21 & miR-34a & Upregulated \\
\hline
\end{tabular}




\section{miRNA modification by diet}

Growing evidence suggests that bioactive dietary components impact epigenetic processes and are often involved with the reactivation of tumor suppressor genes, activation of cell survival proteins, and induction of cellular apoptosis in many types of cancer [47-49]. Recent evidence suggests that bioactive dietary components can also target various oncogenic or tumor suppressive miRNAs to alter the gene expression profile in cancer prevention [50-52]. Genistein, an isoflavone isolated from soybeans, has been reported to have both preventive and therapeutic effects on carcinogenesis and many other diseases [50]. One of the studies performed on ovarian cancer cells, which compared treated and non-treated cells, found that there were a total of 53 miRNAs which were differentially expressed in the cancer cells. Further, upon analyzing gene expression data using real time PCR, both ER$\alpha$ and ER- $\beta$ were observed to be induced in genisteintreated cells, which can correlate with the expression changes of these 53 miRNAs, hence revealing a significant reduction in migration and invasion of ovarian cancer cells. Another investigation used dietary genistein for treatment of uveal melanoma cells and found a time-and dose-dependent inhibition which might be due to inhibition of $m i R-27 a$ [51].

Curcumin (diferuloylmethane), a naturally occurring flavinoid derived from the rhizome of Curcuma longa, has been reported to alter the expression of miRNAs. One such study performed by Sun et. al. found an upregulation of miRNA-22 and down-regulation of miRNA-199a in a pancreatic cancer cell line and a similar study was performed using curcumin in a breast cancer cell line which showed an upregulation of miRNA-15a and miRNA-16 using real time PCR analysis [53].

Epigallocatechin-3-gallate (EGCG) is a major component of green tea and is thought to exert its anticancer effects by epigenetic mechanisms [54]. Studies have shown that EGCG can inhibit epigenetic enzyme activity and thus can modulate apoptosis, the cell cycle and cell proliferation. Recently EGCG is also found to modulate miRNA expression. To further confirm this notion, a study was performed using hepatocellular carcinoma cells and it was found that there is an increase in $m i R-16$ expression which resulted in apoptosis [55].

\section{Conclusion}

miRNAs, a small group of noncoding RNAs, are drawing more attention than ever and are thought to be a new category of tumor suppressors or mediators of signal transduction. Further studies are needed to understand the interactions and regulatory mechanisms between miRNAs and their target molecules. Therefore, it will be important to clarify how the miRNA/SIRT1/p53/DNMT regulatory network is controlled in humans in future research (Table 2). Recent studies have suggested that miRNAs may act as tumor suppressors by regulating various cellular phenomenona like apoptosis, cellular movement, metastasis and cell proliferation. The regulatory loop between SIRT1 and miRNA might provide new opportunities for therapeutic tissue-specific regulation and cancer inhibition. However, the mechanism by which miRNA regulation occurs is still unclear. Besides the involvement of miRNA in cancer, miRNAs may also influenced the aging process and provide a new avenue for potential targets in aging biology. miRNAs are also investigated as early plasma biomarkers and are expected to be more sensitive when compared with current biomarkers. From a clinical perspective, miRNAs can induce diverse effects but care must be exercised when extrapolating findings from in vitro to in vivo. Despite difficulties to overcome, the value of miRNAs in clinical applications is projected to be monumental.

\section{Abbreviations \\ miRNA: Micro RNA; DNMT: DNA methyltransferases; HDAC: Histone deacetylases; HAT: Histone acetylases; SIRT: Silence information regulatory; UTR: Un-translated region; RISC: RNA-induced silencing complex; MESC: Mouse embryonic stem cells; SVR: Support vector regression; NAD: Nicotinamide adenine dinucleotide; FACS: Fluorescence activated cell sorter; EMT: Epithelial to mesenchymal transition; EGCG: Epigallocatechin-3- gallate; PCR: Polymerase chain reaction; 5-FU: 5-fluorouracil; ER: Estrogen receptor.}

\section{Competing interests}

No potential competing interests were disclosed.

\section{Authors' contributions}

Primary author: RK; Author of bioinformatics section: GWP; Edited the manuscript: TMH and TOT. All authors read and approved the final manuscript

\section{Acknowledgements}

This work was supported in part by grants from NCI (R01 CA129425), the American Institute for Cancer Research and a UAB CAS Interdisciplinary Award. Funding for RK and GWP was provided by the UAB Department of Biology; Funding for TMH was provided by NIH NIGMS 5K12GM088010 Noe (PI).

\section{Author details}

'Department of Biology, University of Alabama Birmingham, 1300 University Boulevard, Birmingham, AL 35294, USA. ${ }^{2}$ Center for Aging, University of Alabama Birmingham, 1530 3rd Avenue South, Birmingham, AL 35294, USA. ${ }^{3}$ Comprehensive Cancer Center, University of Alabama Birmingham, 1802 6th Avenue South, Birmingham, AL 35294, USA. ${ }^{4}$ Nutrition Obesity Research Center, University ofs Alabama Birmingham, 1675 University Boulevard, Birmingham, AL 35294, USA. ${ }^{5}$ Comprehensive Diabetes Center, University of Alabama Birmingham, 1825 University Boulevard, Birmingham, AL 35294, USA.

Received: 30 December 2012 Accepted: 4 February 2013 Published: 16 March 2013

\section{References}

1. Grady WM, Tewari M: The next thing in prognostic molecular markers: microRNA signatures of cancer. Gut 2010, 59(6):706-708.

2. Lee Y, Kim M, Han J, Yeom KH, Lee S, Baek SH, Kim VN: MicroRNA genes are transcribed by RNA polymerase II. EMBO J 2004, 23(20):4051-60. 
3. Filippov V, Solovyev V, Filippova M, Gill SS: A novel type of RNase III family proteins in eukaryotes. Gene 2000, 245(1):213-21.

4. Snyder LL, Ahmed I, Steel LF: RNA polymerase III can drive polycistronic expression of functional interfering RNAs designed to resemble microRNAs. Nucleic Acids Res 2009, 37(19):e127.

5. Kim VN, Han J, Siomi MC: Review Biogenesis of small RNAs in animals. Nat Rev Mol Cell Biol 2009, 10(2):126-39.

6. Bartel DP: Review MicroRNAs: genomics, biogenesis, mechanism, and function. Cell 2004, 116(2):281-97.

7. Guo H, Ingolia NT, Weissman JS, Bartel DP: Mammalian microRNAs predominantly act to decrease target mRNA levels. Nature 2010, 466(7308):835-40.

8. Selbach M, Schwanhäusser B, Thierfelder N, Fang Z, Khanin R, Rajewsky N: Widespread changes in protein synthesis induced by microRNAs. Nature 2008, 455(7209):58-63.

9. Grimson A, Farh KKH, Johnston WK, Garrett-Engele P, Lim LP, Bartel DP. MicroRNA targeting specificity in mammals: determinants beyond seed pairing. Mol Cell 2007, 27:91-105.

10. Lewis $B P$, Burge $C B$, Bartel DP: Conserved seed pairing, often flanked by adenosines, indicates that thousands of human genes are microRNA targets. Cell 2005, 120:15-20.

11. Lin RJ, Lin YC, Chen J, Kuo HH, Chen YY, Diccianni MB, London WB, Chang $\mathrm{CH}$, Yu AL: MicroRNA signature and expression of Dicer and Drosha can predict prognosis and delineate risk groups in neuroblastoma. Cancer Res 2010, 70(20):7841-50.

12. Griffiths-Jones $S$, Grocock RJ, van Dongen S, Bateman A, Enright AJ: MiRBase: microRNA sequences, targets and gene nomenclature. Nucleic Acids Res 2006, 34:D140-D144.

13. Kozomara A, Griffiths-Jones S: MiRBase: integrating microRNA annotation and deep-sequencing data. Nucleic Acids Res 2011, 39:D152-D157.

14. Bartel DP: MicroRNAs: target recognition and regulatory functions. Cell 2009, 136:215-233.

15. Betel D, Wilson M, Gabow A, Marks DS, Sander C: The microRNA.org resource: targets and expression. Nucleic Acids Res 2008, 36:D149-D153.

16. Sethupathy P, Corda B, Hatzigeorgiou AG: TarBase: a comprehensive database of experimentally supported animal microRNA targets. RNA 2006, 12:192-197.

17. Griffiths-Jones S, Saini HK, van Dongen S, Enright AJ: MiRBase: tools for microRNA genomics. Nucleic Acids Res 2008, 36:D154-D158.

18. John B, Enright AJ, Aravin A, Tuschl T, Sander C, Marks DS: Human microRNA targets. PLOS Biol 2004, 2:e363.

19. Hubbard TJP, Aken BL, Ayling S, Ballester B, Beal K, Bragin E, Brent S, Chen Y, Clapham P, Clarke L, Coates G, Fairley S, Fitzgerald S, Fernandez-Banet J, Gordon L, Graf S, Haider S, Hammond M, Holland R, Howe K, Jenkinson A, Johnson N, Kahari A, Keefe D, Keenan S, Kinsella R, Kokocinski F, Kulesha E, Lawson D, Longden I, et al: Ensembl 2009. Nucleic Acids Res 2009, 37:D690-D697.

20. Betel D, Koppal A, Agius P, Sander C, Leslie C: Comprehensive modeling of microRNA targets predicts functional non-conserved and non-canonical sites. Genome Biol 2010, 11:R90.

21. Jiang $Q$, Wang $Y$, Hao $Y$, Juan $L$, Teng $M$, Zhang $X$, Li M, Wang G, Liu Y: miR2Disease: a manually curated database for microRNA deregulation in human disease. Nucleic Acids Res 2009, 37:D98-D104.

22. Wang J, Lu M, Qiu C, Cui Q: TransmiR: a transcription factor-microRNA regulation database. Nucleic Acids Res 2010, 38:D119-D122.

23. Hsu S-D, Lin F-M, Wu W-Y, Liang C, Huang W-C, Chan W-L, Tsai W-T, Chen G-Z, Lee C-J, Chiu C-M, Chien C-H, Wu M-C, Huang C-Y, Tsou A-P, Huang HD: MiRTarBase: a database curates experimentally validated microRNAtarget interactions. Nucleic Acids Res 2011, 39:D163-D169.

24. Gaur A, Jewell DA, Liang Y, Ridzon D, Moore JH, Chen C, Ambros VR, Israel MA: Characterization of MicroRNA expression levels and their biological correlates in human cancer cell lines. Cancer Res 2007, 67:2456-2468

25. Baker EK, Johnstone RW, Zalcberg JR, El-Osta A: Epigenetic changes to the MDR1 locus in response to chemotherapeutic drugs. Oncogene 2005, 24(54):8061-75.

26. Roberti A, La Sala D, Cinti C: Multiple genetic and epigenetic interacting mechanisms contribute to clonally selection of drug-resistant tumors: current views and new therapeutic prospective. J Cell Physio/ 2006, 3:571-81.

27. Zhao J, Lin J, Yang H, Kong W, He L, Ma X, Coppola D, Cheng JO: MicroRNA-221/222 negatively regulates estrogen receptor alpha and is associated with tamoxifen resistance in breast cancer. J Biol Chem 2008, 283(45):31079-86

28. Hanahan D, Weinberg RA: Hallmarks of cancer: the next generation. Cell 2011, 144(5):646-74.

29. Pogribny IP, Beland FA: DNA hypomethylation in the origin and pathogenesis of human diseases. Cell Mol Life Sci 2009, 66(14):2249-61.

30. Guil S, Esteller M: DNA methylomes, histone codes and miRNAs: trying it all together. Int J Biochem Cell Biol 2009, 41(1):87-95.

31. Saito Y, Jones PA: Epigenetic activation of tumor suppressor microRNAs in human cancer cells. Cell Cycle 2006, 19:2220-2.

32. Lujambio A, Calin GA, Villanueva A, Ropero S, Sánchez-Céspedes M, Blanco D, Montuenga LM, Rossi S, Nicoloso MS, Faller WJ, Gallagher WM, Eccles SA, Croce CM, Esteller M: A microRNA DNA methylation signature for human cancer metastasis. Proc Natl Acad Sci USA 2008, 105(36):13556-61.

33. Fabbri M, Garzon R, Cimmino A, Liu Z, Zanesi N, Callegari E, Liu S, Alder H, Costinean S, Fernandez-Cymering C, Volinia S, Guler G, Morrison CD, Chan KK, Marcucci G, Calin GA, Huebner K, Croce CM: MicroRNA-29 family reverts aberrant methylation in lung cancer by targeting DNA methyltransferases 3A and 3B. Eur J Gynaecol Oncol 2009, 6:616-21.

34. Rao X, Di Leva G, Li M, Fang F, Devlin C, Hartman-Frey C, Burow ME, Ivan M, Croce CM, Nephew KP: MicroRNA-221/222 confers breast cancer fulvestrant resistance by regulating multiple signaling pathways. Oncogene 2011, 30(9):1082-97.

35. Sachdeva M, Wu H, Ru P, Hwang L, Trieu V, Mo YY: MicroRNA-101mediated Akt activation and estrogen-independent growth. Oncogene 2011, 30(7):822-31

36. He L, He X, Lim LP, Stanchina E, Xuan Z, Liang Y, et al: A microRNA component of the p53 tumour suppressor network. Nature 2007, 447(7148):1130-4.

37. Xi Y, Shalgi R, Fodstad O, Pilpel Y, Ju J: Differentially regulated micro-RNAs and actively translated messenger RNA transcripts by tumor suppressor p53 in colon cancer. Clin Cancer Res 2006, 12(7):2014-24.

38. Shin S, Cha HJ, Lee EM, Jung JH, Lee SJ, Park IC, Jin YW, An S: MicroRNAs are significantly influenced by p53 and radiation in HCT116 human colon carcinoma cells. Int J Oncol 2009, 34(6):1645-52

39. Munekazu Y, Marcella F, Lowenstein CJ: MiR-34a repression of SIRT regulates apoptosis. Proc Natl Acad Sci USA 2008, 105(36):13421-13426.

40. Xu D, Takeshita F, Hino Y, Fukunaga S, Kudo Y, Tamaki A, Matsunaga J, Takahashi R-U, Takata T, Shimamoto A, Ochiya T, Tahara H: miR-22 represses cancer progression by inducing cellular senescence. J Cell Biol 2011, 193(2):409-424

41. Akao Y, Noguchi S, lio A, Kojima K, Takagi T, Naoe T: Dysregulation of microRNA-34a expression causes drug-resistance to 5 -FU in human colon cancer DLD-1 cells. Cancer Lett 2011, 300(2):197-204

42. Eades G, Yao Y, Yang M, Zhang Y, Chumsri S, Zhou Q: miR-200a regulates SIRT1 expression and epithelial to mesenchymal transition (EMT)-like transformation in mammary epithelial cells. J Biol Chem 2011, 286(29):25992-6002

43. Strum JC, Johnson JH, Ward J, Xie H, Feild J, Hester A, Alford A, Waters KM: MicroRNA 132 Regulates Nutritional Stress-Induced Chemokine Production through Repression of SirT1. Mol Endocrinol 2009, 23:11876-1884.

44. Kheir TB, Futoma-Kazmierczak E, Jacobsen A, Krogh A, Bardram L, Hother $C$ Grønbæk K, Federspiel B, Lund AH, Friis-Hansen L: miR-449 inhibits cell proliferation and is down-regulated in gastric cancer. Mol Cancer 2011, 10:29.

45. Saunders LR, Sharma AD, Tawney J, Nakagawa M, Okita K, Yamanaka S, Willenbring $H$, Verdin E: miRNAs regulate SIRT1 expression during mouse embryonic stem cell differentiation and in adult mouse tissues. Aging (Albany NY) 2010, 2(7):415-431.

46. Saito Y, Liang G, Egger G, Friedman JM, Chuang JC, Coetzee GA, Jones PA: Specific activation of microRNA-127 with downregulation of the protooncogene BCL6 by chromatin-modifying drugs in human cancer cells. Cancer Cell 2006, 9(6):435-43.

47. Landis-Piwowar KR, Huo C, Chen D, Milacic V, Shi G, Chan TH, Dou QP: A novel prodrug of the green tea polyphenol (-)-epigallocatechin-3gallate as a potential anticancer agent. Cancer Res 2007, 67(9):4303-10

48. Li Y, Liu L, Tollefsbol TO: Glucose restriction can extend normal cell lifespan and impair precancerous cell growth through epigenetic control of hTERT and p16 expression. FASEB J 2010, 24(5):1442-53. 
49. Paluszczak J, Krajka-Kuźniak V, Baer-Dubowska W: The effect of dietary polyphenols on the epigenetic regulation of gene expression in MCF7 breast cancer cells. Toxicol Lett 2010, 192(2):119-25.

50. Parker L, Taylor D, Kesterson J, Metzinger D, Gercel-Taylor C: Modulation of microRNA associated with ovarian cancer cells by genistein. Eur J Gynaecol Oncol 2009, 30:616-621.

51. Sun Q, Cong R, Yan H, Gu H, Zeng Y, Liu N, Chen J, Wang B: Genistein inhibits growth of human uveal melanoma cells and affects microRNA27a and target gene expression. Oncol Rep 2009, 22:563-567.

52. Li Y, VandenBoom T, Kong D, Wang Z, Ali S, Philip P, Sarkar F: Upregulation of miR-200 and let- 7 by natural agents leads to the reversal of epithelial-tomesenchymal transition in gemcitabine-resistant pancreatic cancer cells. Cancer Res 2009, 69:6704-6712.

53. Yang J, Cao Y, Sun J, Zhang Y: Curcumin reduces the expression of Bcl-2 by upregulating miR-15a and miR-16 in MCF-7 cells. Med Oncol 2010, 27:1114-8.

54. Meeran SM, Ahmed A, Tollefsbol TO: Epigenetic targets of bioactive dietary components for cancer prevention and therapy. Clin Epigenetics 2010, 1(3-4):101-116.

55. Hardy TM, Tollefsbol TO: Epigenetic diet: impact on the epigenome and cancer. Epigenomics 2011, 3(4):503-518.

doi:10.1186/2043-9113-3-6

Cite this article as: Kala et al:: MicroRNAs: an emerging science in cancer epigenetics. Journal of Clinical Bioinformatics 2013 3:6.

\section{Submit your next manuscript to BioMed Central and take full advantage of:}

- Convenient online submission

- Thorough peer review

- No space constraints or color figure charges

- Immediate publication on acceptance

- Inclusion in PubMed, CAS, Scopus and Google Scholar

- Research which is freely available for redistribution 